\title{
Evaluation of Residual Stresses and Their Influence on Cavitation Erosion Resistance of High Kinetic HVOF and HVAF-Sprayed WC-CoCr Coatings
}

\author{
Tommi Varis $^{1} \cdot$ Tomi Suhonen $^{2} \cdot$ Jarmo Laakso $^{1} \cdot$ Mika Jokipii $^{3} \cdot$ Petri Vuoristo $^{1}$
}

Submitted: 25 November 2019/in revised form: 6 March 2020/Published online: 14 May 2020

(C) The Author(s) 2020

\begin{abstract}
Thermal spray processes have been developing toward lower particle temperature and higher velocity. Latest generation high-velocity oxygen-fuel (HVOF) and high-velocity air-fuel (HVAF) can produce very dense coating structures due to the higher kinetic energy typical for these thermal spray processes. Thermally sprayed coatings usually contain residual stresses, which are formed by a superposition of thermal mismatch, quenching and, in case of high kinetic energy technologies, peening stresses. These stresses may have a significant role on the mechanical response and fatigue behavior of the coating. Understanding these effects is mandatory for damage tolerant coating design and wear performance. For instance, wear-resistant WC-CoCr coatings having high compressive stresses show improved cavitation erosion performance. In this study, comparison of residual stresses in coatings sprayed by various thermal spray systems HVOF (Thermico CJS and Oerlikon Metco DJ Hybrid) and HVAF (Kermetico AcuKote) was made. Residual stresses were determined through thickness by utilizing Tsui and Clyne
\end{abstract}

This article is part of a special topical focus in the Journal of Thermal Spray Technology on Advanced Residual Stress Analysis in Thermal Spray and Cold Spray Processes. This issue was organized by Dr. Vladimir Luzin, Australian Centre for Neutron Scatte

Tommi Varis

tommi.varis@tuni.fi

1 Materials Science and Environmental Engineering, Tampere University Ringgold Standard Institution, Korkeakoulunkatu 6, P.O. Box 589, Tampere 33014, Finland

2 Material Modeling and Ecodesign, VTT Technical Research Centre of Finland, Espoo, Finland

3 Nuclear Reactor Materials, VTT Technical Research Centre of Finland, Espoo, Finland analytical model. The real temperature and deposition stress data were collected in the coating process by in situ technique. That data were used for the model to represent realistic residual stress state of the coating. The cavitation erosion and abrasion wear resistance of the coatings were tested, and relationships between residual stresses and wear resistance were discussed.

Keywords cavitation-resistant coatings - fracture toughness · HVAF · HVOF - in situ monitoring - residual stresses $\cdot$ WC-CoCr

\section{Introduction}

The unique droplet-by-droplet manufacturing process of thermally sprayed coatings may generate relatively high residual stresses, which are necessary to understood and controlled well to avoid residual stresses causing failures during the coating manufacturing process or in use (Ref 13). Some of the latest high kinetic thermal spray processes, such as high-pressure high-velocity oxygen-fuel (HVOF) or high-velocity air-fuel (HVAF), typically produce lower flame temperatures and higher particle velocities compared to traditional HVOF spray devices (Ref 4). The temperature-velocity conditions of the spray particles certainly have a major influence on the coating residual stresses, whose effect on the wear performance is of interest. There have been numerous studies on the effect of residual stresses on interfacial adhesion, wear resistance, and fatigue performance of HVOF and HVAF coatings. Luo et.al. showed that the wear resistance decreased in adhesive wear test (pin-on-disk, POD) when coating tensile stresses grew with increased coating thickness (Ref 5). Studies on fatigue resistance of coatings have shown that the effect of HVOF- 
sprayed carbide coatings may have either positive or negative influence on fatigue life of steel. (Ref 6-9) Positive influence on the fatigue life has been observed with coatings that have been in high compressive residual stresses caused by spray particle shot peening, which is shown to play an important role in preventing the crack initiation within the coating or at the interface between the coating and the substrate (Ref 8). Good cavitation erosion resistance of HVAF coatings has been reported in several other studies, in which this was proposed to be mainly related to the high kinetic energy of the particles (Ref 10-12). Studies on cavitation erosion resistance of WC-CoCr has shown that erosion of HVAF coatings takes place by the mechanism of fatigue crack growth, preferably along the weak lamella boundaries. Continuous impacts resulted in crack propagation, crack growth and material removal in larger blocks. It has been discussed that compressive residual stresses hinder the crack growth and positively influence cavitation erosion resistance of the thermally sprayed coatings (Ref 13-15). However, the residual stresses of coatings have been determined with adequate precision only in few studies yet, thus being able to link the residual stresses to wear performance. This may be attributed to the general limitations on experimental measurements of residual stresses in thermally spray coatings, since the origins of residual stresses are known to be relatively complex.

The origins of residual stresses regarding the coating process are well known (a) quenching stresses, (b) peening stresses, and (c) thermal mismatch stresses. Quenching stresses are tensile (-) and generate from the rapid shrinkage and contraction of the splats during the formation stage of the coating from these splats. Peening stresses are compressive (+) and are known to be originated from the high-velocity impacts of the particles resulting in plastic deformation of the substrate and/or previously deposited coating material. As the quenching stresses and peening stresses generate during the deposition stage, they are referred hereafter to as deposition stresses separated by negative or positive sign, respectively. Thermal mismatch stresses generate in the post-deposition cooling stage due to material mismatch between the coating and the substrate which have different coefficients of thermal expansion (CTE) (Ref 3, 16-21).

Several methods can be used for residual stress measurement and/or estimation. Typically, layer removal techniques, hole thrilling method, bending techniques, x-ray diffraction and neutron diffraction are used as experimental methods in the case of thermally sprayed coatings as well as computational models. All of these methods are useful but have some limitations (Ref 22). By conventional laboratory x-rays only a low depth from the sample surface can be measured. Therefore, determination of through thickness residual stress profiles requires progressive mechanical or chemical layer removal, which makes the measurement of depth profiles time consuming. Furthermore, only crystalline phases, with known elastic parameters can be measured, although coatings often include also amorphous phases. Neutron diffraction method requires relatively thick coatings and is an expensive method. Hole drilling method is one of the most commonly used due to its simplicity, portability and ability to track residual stress variation with depth. Accuracy of the hole drilling method as well as layer removal method is dependent on which calibration coefficients are used; these calibration coefficients of the inhomogeneous coatings do not often exist. The accuracy of hole drilling method for thermally sprayed coatings has been further improved by utilizing finite element analysis to determine the required calibration coefficients (Ref 22-27)

In situ curvature method, by which the coating substrate curvature is measured during spraying, is the only method, which can track the origin of the all residual stresses; quenching or peening, and thermal mismatch (Ref 22). The main limitation of the curvature method is, that the curvature data is not simple to transform into coating stresses. Stoney (Ref 28) or Brenner and Senderoff (Ref 29) equations have been used in many cases for the residual stress estimation although these methods have some assumptions and the accuracy is therefore arguable. Tsui and Clyne (Ref 30) have developed their analytical model to determine residual stresses through thickness for progressively deposited coatings. The model combines quenching or peening and thermal mismatch stresses. However, it requires the deposition stresses and temperature data from the deposition process as input parameters (Ref 22, 24, 3134).

In the present study, the residual stress state of WC$\mathrm{CoCr}$ coatings produced by various high kinetic thermal spray processes was compared by using the Tsui and Clyne model. In combination with in situ curvature technique, which can be used to determine the deposition stresses and measure the temperatures, a realistic estimation of through thickness stresses can be achieved. The main subject of this study is to address the effect of stress state on the cavitation erosion resistance of HVAF- and high-pressure HVOFsprayed WC-CoCr coatings, which has been found to be particularly good. Additively, abrasion wear resistances of the coatings were studied less extensively in order to compare the effect of differently coatings under exposing another type of wear mechanism. In addition, the abrasion resistance of coatings was investigated less extensively to compare the durability of differently processed WC-CoCr coatings under another type of wear mechanism. 


\section{Experimental}

\section{Spraying of the Coatings}

WC-10Co4Cr powder from Durum Verschleiss-Schutz $\mathrm{GmbH}$, Krefeld, Germany was used for the sprayings with AcuKote-07 (AK7) HVAF device (Kermetico Inc., Benicia, CA, USA), and Thermico Carbide Jet Spray (CJS) high-pressure HVOF device (Thermico $\mathrm{GmbH} \& \mathrm{Co}$, Dortmund, Germany) The feedstock used was an agglomerated and sintered powder with a nominal size distribution of 5-25 $\mu \mathrm{m}$, which had a nominal size of 0.4 micron WCparticles in the CoCr matrix. For spraying with Diamond Jet Hybrid 2700 (DJH 2700) spray device (OerlikonMetco, Westbury, NY, USA) the similar type of WC$10 \mathrm{Co} 4 \mathrm{Cr}$ powder from Durum was used. This powder had nominal particle size distribution $15-36 \mu \mathrm{m}$, and the nominal carbide size was $0.4 \mu \mathrm{m}$ too.

Spray parameters for the Diamond Jet Hybrid 2700 (later HVOF 1) process were selected based on the recommendation of the equipment manufacturer. For the Thermico Carbide Jet Spray (later HVOF 2), three parameters (HVOF 2A, 2B, and 2C) with different kerosene levels, 14, 16, and $18 \mathrm{~m}^{3} \mathrm{~h}^{-1}$ were selected. Kerosene flow is known to affect the flame temperature strongly. Kerosene level alteration was compensated with oxygen adjustment targeting to maintain combustion chamber pressure and this way keep the particle velocity relatively constant. For the AcuKote HVAF (later HVAF) process, the operating window for the adjustment of fuel-oxygen ratio was relatively limited. Therefore, particle conditions were to be affected by increasing the pressures of the gases fed to the HVAF gun and hence keeping the ratio in the accessible range. This increases the chamber pressure, which is expected to give the particles higher velocity (shorter dwell time) and higher temperatures. Three parameters were selected for HVAF (HVAF A, B, and C), which had increasing chamber pressures. The spray parameters are presented in Table 1. Particle temperature and velocity (Table 1) were measured with Spray Watch $2 \mathrm{i}$ (Oseir Oy, Tampere, Finland) in case of both HVOF processes and Spray Watch 4i (Oseir Oy, Tampere, Finland) in case of HVAF, which confirmed that parameter adjustments affect the particles as earlier presented.

The coatings were deposited on S355 low carbon steel flat bars of $228.6 \mathrm{~mm}$ in length, $25.4 \mathrm{~mm}$ in width, and $2.5 \mathrm{~mm}$ thick, which were grit blasted on both sides by using the size of 500-700 $\mu \mathrm{m}$ corundum particles. Gun traverse speed of $1 \mathrm{~m} \mathrm{~s}^{-1}$ and step width of $4 \mathrm{~mm}$ was used. Deposition was evaluated in situ using in-situ coating property (ICP) sensor (Ref 2) by ReliaCoat Technologies, East Setauket, NY, USA. The ICP sensor measures the temperature and curvature of the substrate beam during spraying. Details of the technology are given below.

\section{Characterization of Microstructure and Mechanical Properties}

The polished cross-sectional samples of the coatings and worn surfaces in the erosion test were characterized with a Zeiss ULTRA plus field-emission scanning electron microscope (Carl Zeiss AG, Oberkochen, Germany) using accelerating voltage of $15 \mathrm{kV}$. The porosities of the coatings were measured from the backscatter images using ImageJ software. The lateral depth of the surface craters after the wear tests was analyzed from the $0.81 \times 0.81 \mathrm{~mm}^{2}$ area with an optical profilometer (InfiniteFocus G5, Alicona Imaging GmbH, Austria). The phase compositions of the coatings were determined by $\mathrm{x}$ ray diffractometry (XRD: Empyrean, PANalytical, Netherlands) using $\mathrm{Cu}-\mathrm{K} \alpha$ radiation (1.5406 $\AA, 40 \mathrm{kV}$ and $45 \mathrm{~mA}$ ). Phase identification was done with HighScorePLUS software (PANalytical, Netherlands). Coating hardness and elastic modulus were measured using an instrumented indenter (Zwick ZHU 0.2, Zwick-Roell, Ulm, Germany) with a Vickers tip. Hardness and indentation modulus were measured on the polished cross sections at a load of $300 \mathrm{~g}$. Ten indentations were performed on each coating. Elastic modulus was calculated from the loaddisplacement data taken from the indentations at the coating cross section following the procedure proposed by Oliver and Pharr (Ref 35). For fracture toughness determination, ten indents were taken on polished cross sections at a load of $5 \mathrm{~kg}$. Corner crack lengths of the indents were analyzed by optical microscopy, and the fracture toughness's were calculated by the equation proposed by Lankford (1) (Ref 36):

$K_{\mathrm{IC}}=0,0363(E / \mathrm{HV})^{\frac{2}{5}} \cdot\left(P / a^{1.5}\right) \cdot(a / c)^{1.56}$,

where $E$ is indentation modulus with $0.3 \mathrm{~kg}$, $\mathrm{HV}$ is Vickers hardness with $0.3 \mathrm{~kg}, P$ is indentation load, $a$ is half-length of the indentation diagonal and, $c$ is average crack length measured from the center of the imprint of the indent. Equation 1 is valid for both crack modes: radial cracks (known as Plamqvist cracks) formed radially from the corners of the imprint and median cracks formed with higher loads under the pyramid tip.

\section{Wear Tests}

Cavitation erosion tests were performed with an ultrasonic transducer (VCX-750, Sonics \& Materials, USA) according to the ASTM G32-16 standard for indirect cavitation erosion. The vibration tip was an alloy of Ti-6Al-4 V and 
Table 1 Spray parameters used for the deposition of the coatings, corresponding particle temperature and velocity, and resulting coating thicknesses

\begin{tabular}{|c|c|c|c|c|c|c|c|}
\hline & HVOF 1 & HVOF 2 A & HVOF 2 B & HVOF $2 \mathrm{C}$ & HVAF A & HVAF B & HVAF C \\
\hline Propane pressure, $\mathrm{kPa}$ & $\ldots$ & $\ldots$ & $\ldots$ & $\ldots$ & 517 & 600 & 676 \\
\hline Propane flow, $\mathrm{L} \mathrm{min}^{-1}$ & $\ldots$ & $\ldots$ & $\ldots$ & $\ldots$ & 94 & 106 & 134 \\
\hline Air pressure, $\mathrm{kPa}$ & $\cdots$ & $\cdots$ & $\cdots$ & $\ldots$ & 648 & 758 & 827 \\
\hline Kerosene flow, $\mathrm{m}^{3} \mathrm{~h}^{-1}$ & $\ldots$ & 14 & 16 & 18 & $\ldots$ & $\ldots$ & $\ldots$ \\
\hline Oxygen flow, $\mathrm{L} \min ^{-1}$ & 215 & 960 & 940 & 920 & $\ldots$ & $\ldots$ & $\ldots$ \\
\hline Air flow, $\mathrm{L} \min ^{-1}$ & 350 & & & & $\ldots$ & $\ldots$ & $\ldots$ \\
\hline Hydrogen flow, $\mathrm{L} \min ^{-1}$ & 635 & 80 & 80 & 80 & 35 & 35 & 35 \\
\hline Nitrogen flow, $\mathrm{L} \min ^{-1}$ & 15 & $16+16$ & $16+16$ & $16+16$ & 35 & 35 & 35 \\
\hline Chamber pressure, $\mathrm{kPa}$ & 538 & 1358 & 1338 & 1331 & 469 & 545 & 600 \\
\hline Stand off distance, $\mathrm{mm}$ & 230 & 200 & 200 & 200 & 250 & 250 & 250 \\
\hline Particle temperature, ${ }^{\circ} \mathrm{C}$ & 1867 & 1643 & 1732 & 1785 & 1500 & 1510 & 1630 \\
\hline Particle velocity, $\mathrm{m} \mathrm{s}^{-1}$ & 621 & 844 & 872 & 851 & 798 & 835 & 908 \\
\hline Powder feed rate, $\mathrm{g} \mathrm{min}^{-1}$ & 40 & 69 & 68 & 67 & 95 & 94 & 97 \\
\hline Thickness, $\mu \mathrm{m}$ & 350 & 275 & 340 & 370 & 380 & 330 & 310 \\
\hline Number of passes & 26 & 34 & 34 & 34 & 30 & 30 & 30 \\
\hline
\end{tabular}

tip diameter was $13 \mathrm{~mm}$. In the test, the frequency was $20 \mathrm{kHz}$, amplitude $50 \mu \mathrm{m}$. Samples were attached at $0.5 \mathrm{~mm}$ distance of the transducer and water temperature was kept at $25^{\circ} \mathrm{C}$. The coating surfaces were ground flat and polished with a polishing cloth and $3 \mu \mathrm{m}$ diamond suspension to produce a mirror finish. Samples were cleansed in an ultrasonic bath with ethanol, dried, and weighed after $0,2,4$, and $6 \mathrm{~h}$. Volume loss rate $\left(\mathrm{mm}^{3}\right.$ $\min ^{-1}$ ) was determined from the cumulative volume loss curve by using linear fitting. The material densities used for calculating the volume losses from the weight losses was $14.6 \mathrm{~g} \mathrm{~cm}^{-1}$. The volume losses were further divided by the tip area of $123 \mathrm{~mm}^{2}$ and multiplied by a 1000 to get the maximum rate of erosion $\left(\mu \mathrm{m} \mathrm{h} \mathrm{h}^{-1}\right)$.

Rubber wheel abrasion tests were performed according to ASTM G65 procedure $D$. Prior to testing samples were ground to a surface finish of Ra 0.3. Samples were placed in contact against a rubber wheel at a static force of $45 \mathrm{~N}$. A rubber wheel of $227 \mathrm{~mm}$ diameter was used at $200 \mathrm{rpm}$ for a total sliding distance of $4.279 \mathrm{~m}$ (6.000 revolutions). The quartz sand used consisted of rounded particles with an average size between 212 and $300 \mu \mathrm{m}$. Sand mass flow rate was $270 \mathrm{~g} \mathrm{~min}^{-1}$. One sample per coating was tested.

\section{Determination of Residual Stresses}

An ICP-sensor monitors the curvature and temperature of a flat bar sample during the deposition process. Three lasers in the center and $45 \mathrm{~mm}$ from the both ends of the beam detect the curvature. A simultaneous measurement of temperature was recorded via multiple thermocouples.
Laser data was converted to the sample curvature, which can be used to determine the stresses evolved during deposition and cooling. Average deposition stresses and thermal mismatch stresses inside the coating was calculated by Brenner and Senderoff's equation (Ref 29) for thick coatings (2):

$\sigma_{\mathrm{c}}=\frac{E_{\mathrm{s}}^{\prime} t_{\mathrm{s}}\left(t_{\mathrm{s}}+\beta^{1.25} d t_{c}\right)}{6 d R d t_{\mathrm{c}}} ; \beta=\frac{E_{\mathrm{c}}^{\prime}}{E_{\mathrm{s}}^{\prime}}$

where $\sigma_{\mathrm{c}}$ is the average stress in the coating, $E_{\mathrm{c}}{ }^{\prime}$ is the inplane modulus of the coating, $E_{\mathrm{s}}{ }^{\prime}$ is in-plane modulus of the substrate, $t_{\mathrm{s}}$ is thickness substrate and $d R$ is change in radius caused by deposition of layer thickness $d t_{\mathrm{c}}$. Deposition stresses were calculated from the initial curvature $(0)$ to the curvature, which exists immediately after deposition, while the thermal stresses were calculated from the end of spraying to the cooling down of the substrate-coating system to final curvature at $30{ }^{\circ} \mathrm{C}$. The final average stress in the coating is the sum of the deposition stresses and thermal mismatch stresses. The material-specific values for WC-CoCr and steel, which were used to calculate the stresses with Eq 2-5 are presented in Table 2.

Residual stress distribution in the coating was determined by Tsui-Clyne analytic model. Compared to the Brenner and Senderoff's equation, it results in through thickness residual stress data. In addition, the effect of varying substrate temperatures on the residual stresses can be considered. In the following it will be only explained how the model was used in the scope of this study, while the complete description of the model can be found in its original source (Ref 30). The model considers the 
Table 2 Material-specific values for $\mathrm{WC}-\mathrm{CoCr}$ and steel used for calculations

\begin{tabular}{lcc}
\hline & Steel substrate & WC-CoCr coating \\
\hline Young's modulus, GPa & 200 & In Table 4 \\
Coefficient of thermal expansion, $10^{-6} \mathrm{C}^{-1}$ & 11 & $5.2^{\mathrm{a}}$ \\
Poisson's ratio & 0.3 & 0.22 \\
\hline
\end{tabular}

${ }^{\mathrm{a}} \operatorname{Ref} 40$ deposition stresses generated by each individual coating layer, as well as the stresses caused by the different thermal expansion coefficients of the coating and substrate. The model determines the stress in the middle of the coating layer and can be calculated between the first and last coating layers $(1<j<n)$. For example deposition stress in the middle of the $\mathrm{n}^{\text {th }}$ layer (last deposited layer) can be calculated by using formula (3) (Ref 30$)$ :

$\sigma_{\mathrm{dn}}=\frac{F_{n}}{b w}-E_{\mathrm{d}}\left(\kappa_{n}-\kappa_{n-1}\right)\left(\left(n-\frac{1}{2}\right) w-\delta_{n}\right)$,

where $F_{n}=$ normal force, $b=$ beam width, $w=$ layer thickness, $E_{\mathrm{d}}=$ Young's modulus of the deposit, $\kappa_{n}-\kappa_{n-1}=$ curvature change due to the deposition of layer $\mathrm{n}, \delta_{n}=$ location of neutral axis. Each deposited layer causes deposition stresses, either being of peening or quenching nature, which either increases or decreases the stresses of underlying layers, respectively. The stress of these layers are added to the underlying layer by superposing the effect of each following layer by (4) (Ref 30):

$\sigma_{i}=\sum_{i=j+1}^{n}\left(\frac{-E_{\mathrm{d}} F_{i}}{b\left(H E_{\mathrm{s}}+(i-1) w E_{\mathrm{d}}\right)}-E_{\mathrm{d}}\left(\kappa_{i}-\kappa_{i-1}\right)\left(j-\frac{1}{2}\right) w-\delta_{1}\right)$,

where $1<j<n, E_{\mathrm{s}}=$ Young's modulus of the substrate and $H=$ thickness substrate. The normal force $\left(F_{n}\right)$ for each layer in Eq 3 and normal force $\left(F_{i}\right.$, found by replacing $\mathrm{n}$ with i) in Eq 4 for following layers is calculated by using Eq $5(\operatorname{Ref} 30)$ :

$F_{n}=\sigma_{\mathrm{d}} b w\left[\frac{H E_{\mathrm{s}}+(n-1) w E_{\mathrm{d}}}{H E_{\mathrm{s}}+n w E_{\mathrm{d}}}\right]$,

where term $\sigma_{\mathrm{d}}$ is the deposition stress, which is needed to be determined in order to further calculate the stresses in each layer. In this case, an iteration process described by Tsui and Clyne (Ref 37) was used, in which the deposition stresses were adjusted as such, that the measured curvatures from the ICP sensor and the curvatures from the Tsui and Clyne model were equal. Only that part of the curvature curve was used, where the temperature was constant, and curvature caused by each pass was changing relatively linearly. In practice, this meant curvature change between the passes 5 and 25 .
Stresses due to CTE mismatch can be determined if the decline in temperature, the specimen dimensions, the Young's modulus and the CTEs of the materials are known from Eq 6 (Ref 30):

$\sigma_{\mathrm{CTE}}=\frac{F_{(\mathrm{CTE})}}{b h}-E_{\mathrm{d}}\left(\kappa_{j}-\kappa_{n}\right)\left(\left(j-\frac{1}{2}\right) w-\delta_{n}\right)$

where $\mathrm{F}_{(\mathrm{CTE})}$ is a balancing force due to CTE mismatches, and other symbols as earlier. The calculation of the thermal mismatch stresses can be found more detailed in the original source (Ref 30$)$.

Finally, the stress in the middle of each coating layer was calculated by superposing the stresses from (a) the layer in question, (b) stresses caused by layers deposited after layer in question, and (c) thermal mismatch stresses during the cool down. In these calculations, the only modification on the original procedure was that the actual temperature before each pass was used instead of a constant temperature. The temperature was recorded by ICP from the back of the flat steel bar. This allows capturing the effect of altering temperature on the residual stress profile. Often at the beginning of the spray process the temperature increases until it stabilizes on a certain level for the rest of the deposition.

As a summary, in this case the residual stresses distribution inside the coatings was determined by using Tsui and Clyne analytical model with following procedure: (a) The deposition stresses either quenching or peening were determined by iterating the deposition stress by using the real curvature data from the ICP, (b) through thickness stresses were calculated for progressive deposited coatings (Eq 3, 4, and 5), (c) the temperature data before each coating layer was used for the calculation of the thermal mismatch stresses (Eq 5) and (d) stresses from (b) and (c) were superposed.

\section{Results}

\section{Coating Microstructures and Phase Compositions}

The microstructures of the coatings with the measured porosity in the upper right corner of the image are shown in Fig. 1. Coatings HVOF 2 and HVAF are very dense and only some minor micro-porosity in the coatings can be 
detected. Although the porosity of all coatings is relatively low, there is a clear difference in pore size and location between HVAF/HVOF 2 and HVOF 1 coatings. In HVAF and HVOF 2 coatings, the pores are small and evenly distributed in the coating structure. HVOF 1 coating clearly has larger size pores and some microcracking, which are concentrated on interlamellar region. HVAF coatings are the densest and have a lower porosity as the particle velocity increases. Regarding to HVOF 2 process, it can be stated that the coldest spraying parameter $(A)$ does not sufficiently compact the initial porosity of the powder which has remained in the coating structure.

Further observations on coating structures can be made based on the XRD analysis and contrast differences. There are two mechanisms for WC-CoCr coatings, which change the coating microstructure. These can be detected either from the microstructure or from the XRD: (a) carbon loss reactions and (b) dissolution of carbide into a liquid matrix. In general, heavier elements appear brighter in SEM backscattering images. Thus, dissolution of $\mathrm{W}$ can be estimated to some extent from contrast differences. Carbon loss results in a formation of $\mathrm{W}_{2} \mathrm{C}$ on the surface of original WC, which is detectable by XRD. In all the coatings, some of the WC is dissolute into the matrix, which appears lighter after intake of tungsten. In HVAF process, due to lower flame temperature and longer residence time compared to HVOF 2 process particles the particles have heated more evenly and coatings shows relatively homogenous microstructure and no major differences between parameters A, B, and C was found. The HVOF 2 coatings are more inhomogeneous compared to the HVAF coatings. Carbide dissolution into the matrix seems to be more concentrated on the surface of the particles, which causes the visible concentration difference between the inner and outer regions of the lamellae. In the HVOF 1, coating significant amount of carbide dissolution was evident in the microstructure and small carbides are missing inside the microstructure. The $\mathrm{W}_{2} \mathrm{C}$ peak in Fig. 2 (location of $2 \theta=40^{\circ}$ ) for $\mathrm{HVOF} 1$ coating the highest among all coatings. Other coatings contained an increasing amount of $\mathrm{W}_{2} \mathrm{C}$ with the increasing measured particle temperature resulting from decarburization process, but to such an extent that it has no significant effect on the coating properties. Other observations from the XRD are that the HVOF $2 \mathrm{~A}$ coating has either a visible $\mathrm{Co}_{3} \mathrm{~W}_{3} \mathrm{C}$ - or $\mathrm{Co} / \mathrm{Cr}-$ peak (location of $2 \theta=42.7^{\circ}$ ), which most probably originates from the powder, and shows that the heating of the particles during the deposition of HVOF $2 \mathrm{~A}$ coating has been the lowest among all coatings. For all of the coatings except for HVOF $2 \mathrm{~A}$, there was also a notable increase in the background intensity between $2 \theta$ angles $35^{\circ}$ and $45^{\circ}$, from the formation of amorphous and nanocrystalline phases due to carbide dissolution can be inferred (Ref 38).

\section{Curvature and Temperature Measurements and Calculated Residual Stresses}

Table 3 presents the deposition stress, thermal mismatch stresses and final residual stresses at the surface of the coating evaluated by Tsui and Clyne model and average residual stresses by Brenner and Senderoff equation. The temperature and curvature curves from the ICP device are presented in Fig. 3 and corresponding residual stresses at the coating surface according to Tsui and Clyne-model in Fig. 4. Through thickness residual stresses of the coatings by Tsui and Clyne analytical model are given in Fig. 5 .

The coating HVOF 1 shows the increasing convex (positive) curvature during spraying, which means that negative deposition stresses (tensile quenching stresses) are dominating during the spraying process. During the cool down, the beam convexity decrease and the coating shifts toward a lower tensile stress state. After the cool down, the beam is still convex and final residual stress in HVOF 1 coating is tensile, compare Figs. 3 and 4. The average residual stress in the coating by Brenner and Senderoff equation was $+166 \mathrm{MPa}$. Tsui and Clyne through thickness residual stress profile shows increasing tensile stress toward the coating surface as the thickness increases. The residual stress on the surface was $+299 \mathrm{MPa}$ for HVOF 1 process.

In contrast to HVOF 1, HVOF 2 and HVAF processes produced negative or very slight positive curvature during the deposition stage, which shows that compressive deposition stresses were mainly dominant. Post-deposition thermal mismatch stresses for HVOF 2 developed similarly as for HVOF 1 and are almost constant across variations. For HVAF, thermal mismatch stresses were higher due to the higher deposition temperature and decreased with rising particle velocity. The final average residual stresses determined by Brenner and Senderoff equation varied from - 404 to $-652 \mathrm{MPa}$ for HVOF 2 and from -422 to - $965 \mathrm{MPa}$ for HVAF. The residual stress on the surface of HVOF 2 and HVAF coatings according to Tsui and Clyne model were highly compressive varying from -281 to $-586 \mathrm{MPa}$ and -289 to $-628 \mathrm{MPa}$, respectively.

As it is shown in Table 1, the particle temperatures in the HVOF 2 process were higher, when the kerosene level was increased, while the particle velocities were comparable. Having higher kerosene flows causes higher flame temperature, which heats up the substrates more and thus results in higher thermal mismatch stress during cool down. From the HVOF 2 curvature changes in Fig. 3, lower particle temperatures increase the peening effect during the deposition as a negative curvature change is developing in the HVOF $2 \mathrm{~B}$ and $2 \mathrm{~A}$ coatings. For the HVOF 2 coatings it was evident that a lower flame temperature correlates with higher developed compressive deposition stresses, which is 

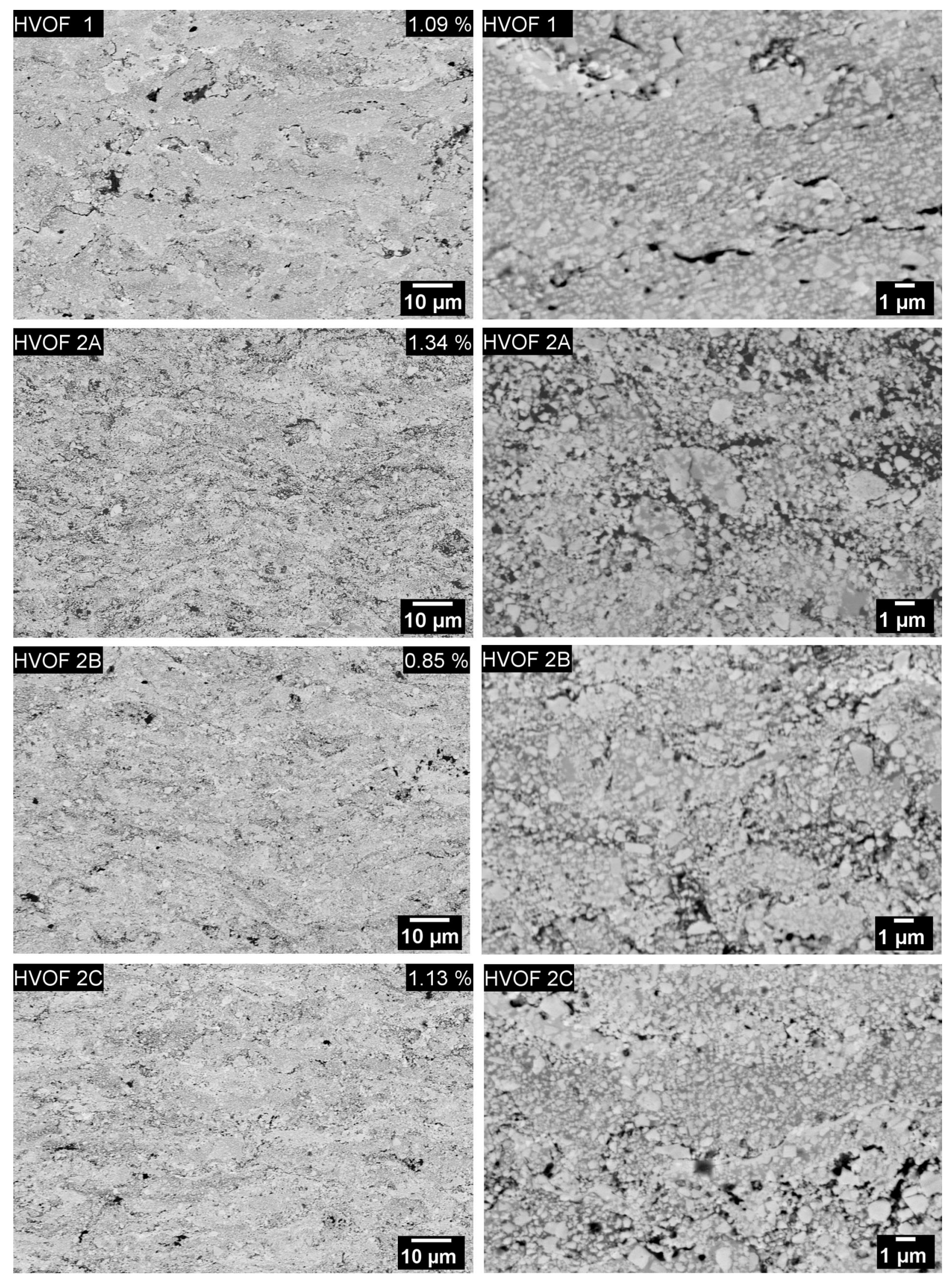

Fig. 1 Microstructures of the coatings by scanning electron microscope with backscatter detector. Porosity, if measured, in the upper right corner of the image 

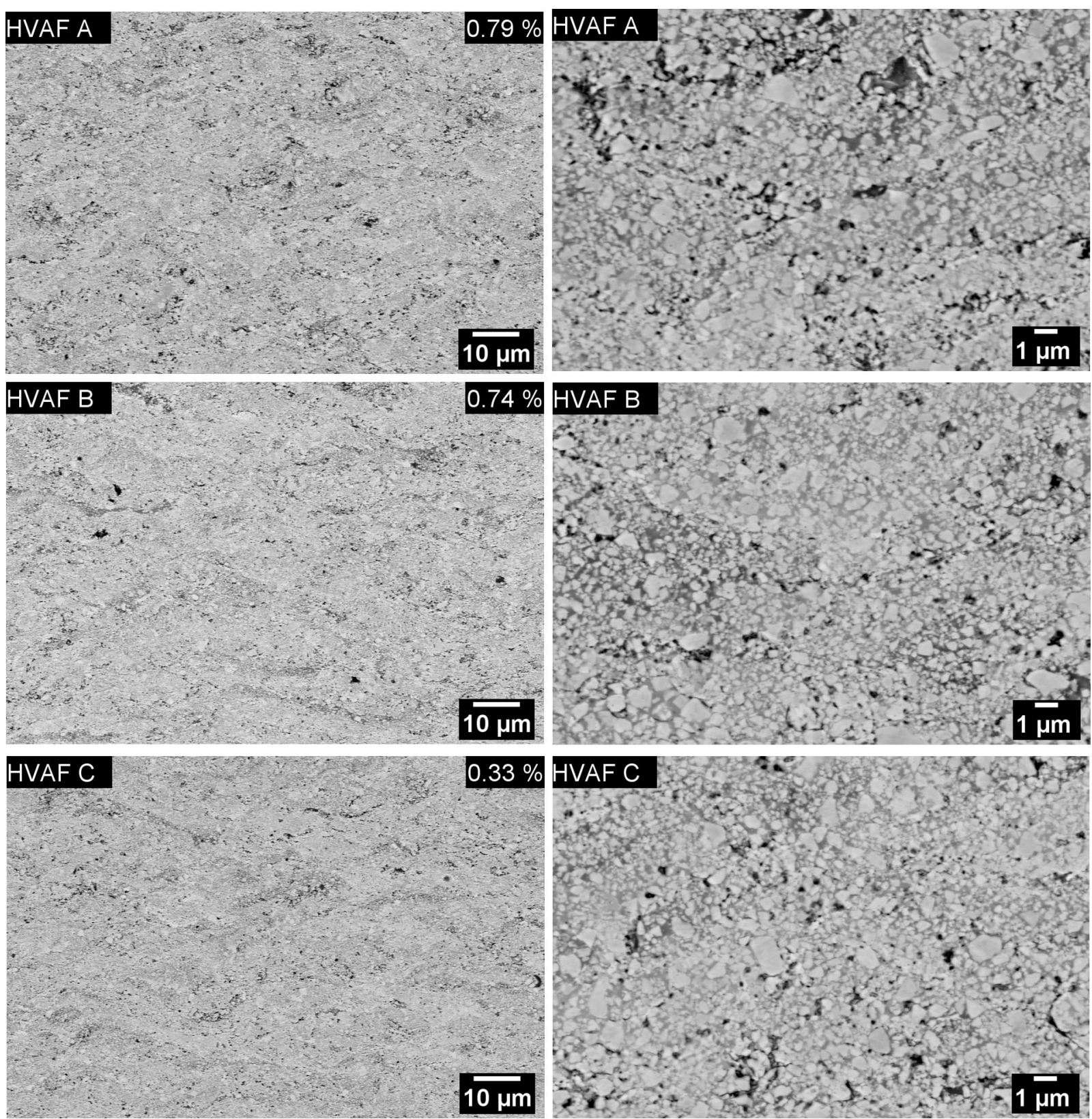

Fig. 1 continued

summarized in Fig. 4. It was noticed that the HVOF 2A coating had the highest amount of positive deposition stresses (peening stresses) among all coatings.

In the HVAF deposition (Fig. 3), rapid curvature changes to a positive direction during the first 4-5 passes were seen, which can obviously be attributed to a simultaneous temperature increase. The effect of the temperature during early passes on the residual stresses can be seen in through thickness residual stress profile in Fig. 5. It shows lower compressive stresses for the first passes than for subsequent passes. For HVAF, the particle temperature and velocity both increased from parameters A to B to C. From the curvature curves in Fig. 3 and Brenner and Senderoff presentation in Table 3 for HVAF, lowest particle $\mathrm{T}$ and $\mathrm{v}$ parameter (HVAF A) produces tensile deposition stresses while the highest $\mathrm{T}$ and $\mathrm{v}$ parameter (HVAF C) results in compressive deposition stress.

\section{Mechanical Properties and Wear}

Mechanical properties and wear resistances of the coatings are shown in Table 4. Hardness and elastic modulus are clearly the highest for the HVAF coatings and relatively similar for the both HVOF coatings. Fracture toughness 

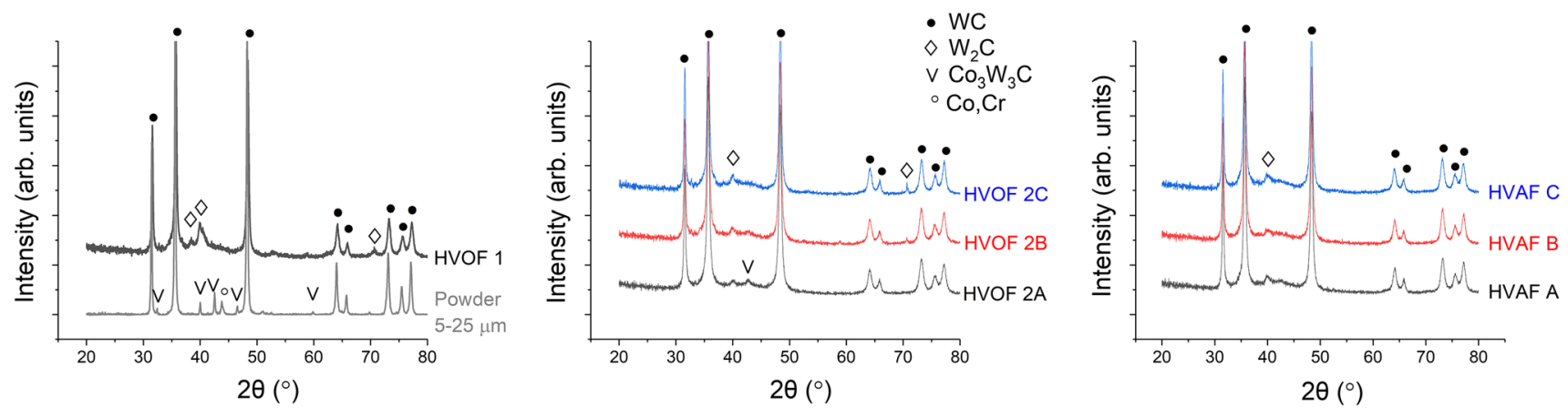

Fig. 2 XRD patterns of the coatings

Table 3 Average residual stresses of the coatings by Brenner and Senderoff $(B \& S)$ approximation, and surface residual stresses by Tsui and Clyne $(\mathrm{T} \& \mathrm{C})$ model $(+$ tensile and - compressive)

\begin{tabular}{|c|c|c|c|c|c|c|}
\hline \multirow[t]{2}{*}{ Coating } & \multicolumn{2}{|c|}{ Deposition stress, MPa } & \multicolumn{2}{|c|}{ Thermal mismatch stress, $\mathrm{MPa}$} & \multicolumn{2}{|c|}{ Final residual stress, $\mathrm{MPa}$} \\
\hline & $\begin{array}{c}\mathrm{T} \& \mathrm{C} \\
\text { (on surface) }\end{array}$ & $\begin{array}{c}\text { B\&S } \\
\text { (average) }\end{array}$ & $\begin{array}{c}\mathrm{T} \& \mathrm{C} \\
\text { (on surface) }\end{array}$ & $\begin{array}{c}\text { B\&S } \\
\text { (average) }\end{array}$ & $\begin{array}{c}\mathrm{T} \& \mathrm{C} \\
\text { (on surface) }\end{array}$ & $\begin{array}{c}\mathrm{B} \& \mathrm{~S} \\
\text { (average) }\end{array}$ \\
\hline HVOF 1 & +553 & +498 & -254 & -332 & +299 & +166 \\
\hline HVOF $2 \mathrm{~A}$ & -369 & -302 & -217 & -349 & -586 & -652 \\
\hline HVOF 2 B & -181 & -129 & -225 & -364 & -406 & -493 \\
\hline HVOF $2 \mathrm{C}$ & -61 & -24 & -219 & -381 & -281 & -404 \\
\hline HVAF A & +18 & +147 & -307 & -568 & -289 & -422 \\
\hline HVAF B & -121 & +1.1 & -373 & -711 & -494 & -710 \\
\hline HVAF C & -192 & 30.5 & -436 & -995 & -628 & -965 \\
\hline
\end{tabular}

HVOF 2
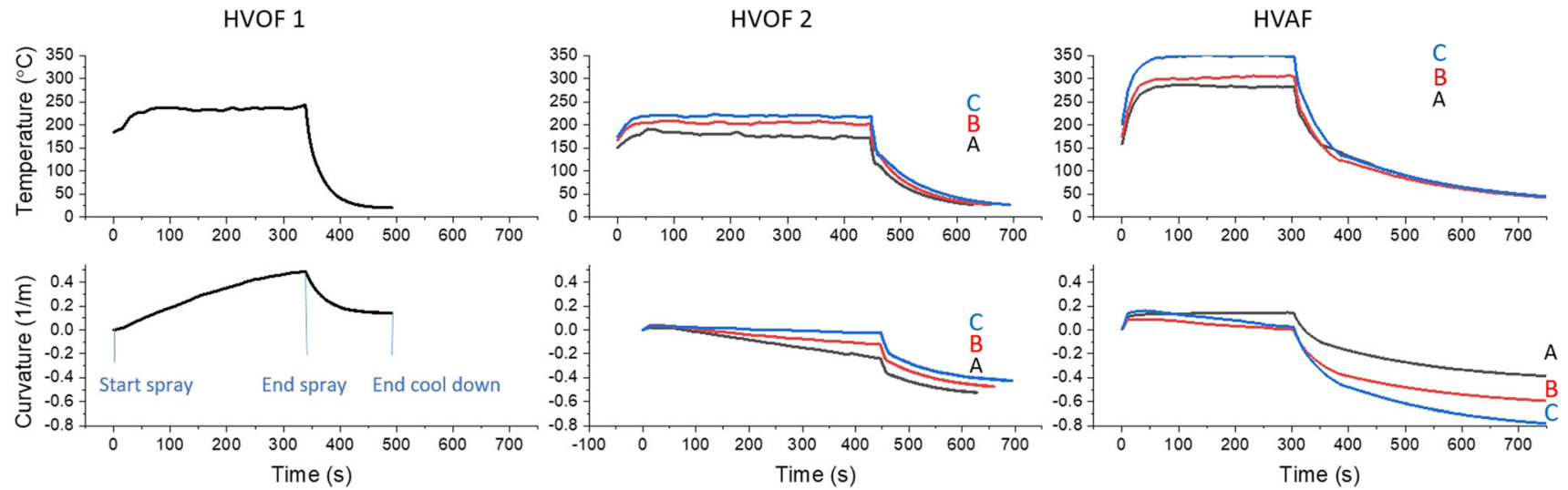

Fig. 3 Temperature and curvature of the deposited samples measured in situ by ICP-sensor

results with $5 \mathrm{~kg}$ loads show significant differences between coatings. The best coatings, HVAF $2 \mathrm{~B}$, HVOF $2 \mathrm{C}$ and HVAF A, had very good fracture toughness's while HVAF B and C had surprisingly low fracture toughness's. HVAF B and C coatings had crack lengths typical of "halfpenny"-type cracking while other coatings had crack lengths typical of Palmqvist type cracking. The abrasion wear resistances of the coatings, in Fig. 6(b), did not vary significantly, while significant differences in the cavitation erosion resistance was evident in Fig. 6(a). Compared to the HVOF 1 coatings, of HVOF 2 coatings had 4-5 times and HVAF coatings even 7-11 times better cavitation erosion resistances.

SEM studies revealed a clear difference in remained non-eroded surface areas of the eroded surfaces of coatings depending on the spray method used as shown in Fig. 7. Coatings sprayed by HVAF process had large amount of non-eroded surface after the $6 \mathrm{~h}$ of erosion and HVOF 2 coatings had some. HVOF 1 coatings surface was almost completely eroded. It was clear that at the areas where the surface of the coating had the appearance of an original polished surface there were no signs of matrix or carbide removal. In the worn, area fractured surfaces and already 
HVOF 1

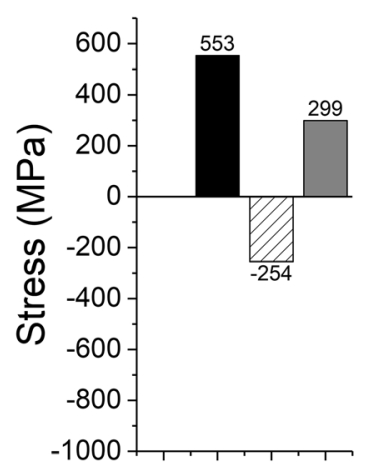

(a)

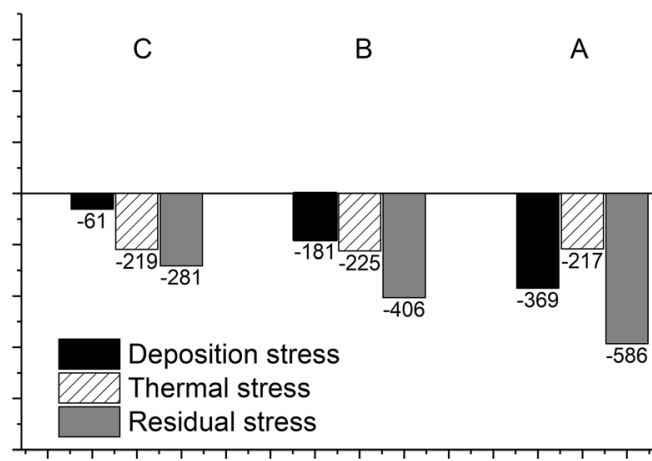

HVAF

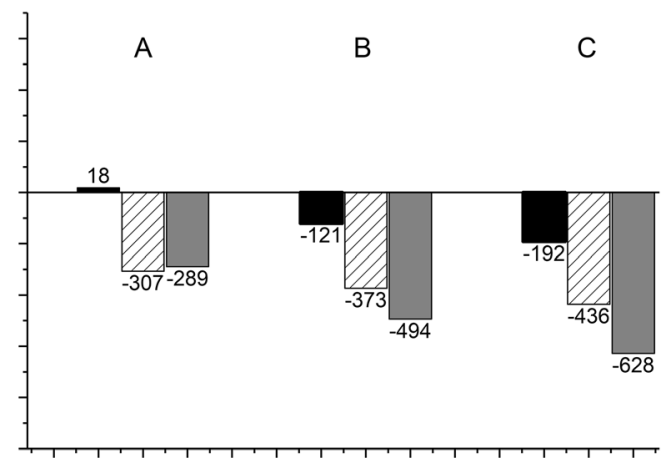

HVOF 2
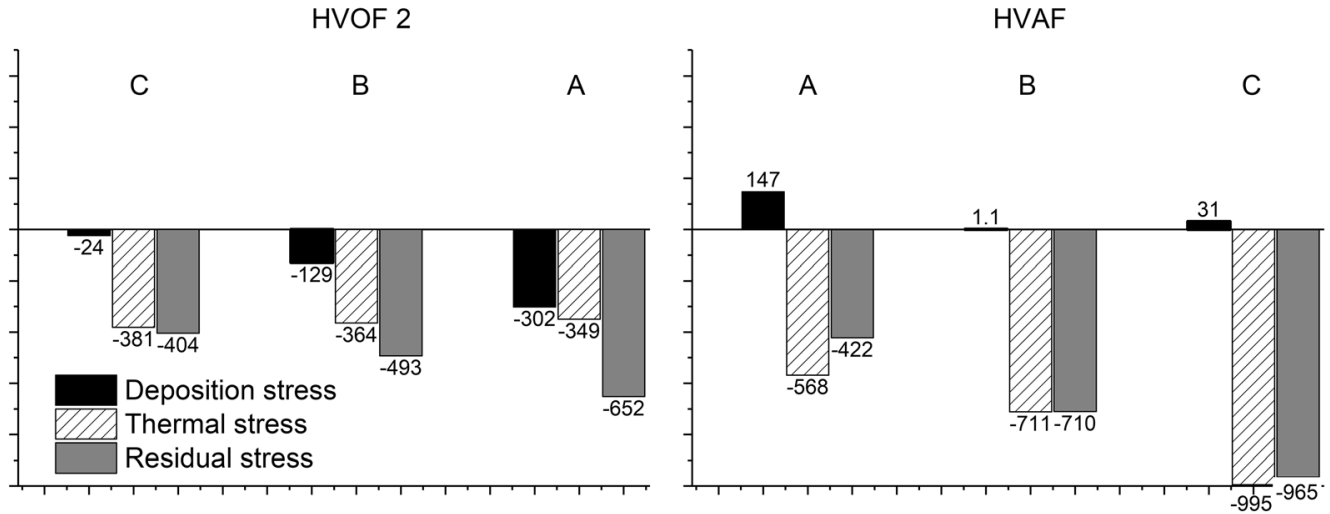

(b)

Fig. 4 Deposition stresses, thermal stresses and final residual stresses at the surface of the coatings by (a) Tsui and Clyne and (b) Brenner and Senderoff

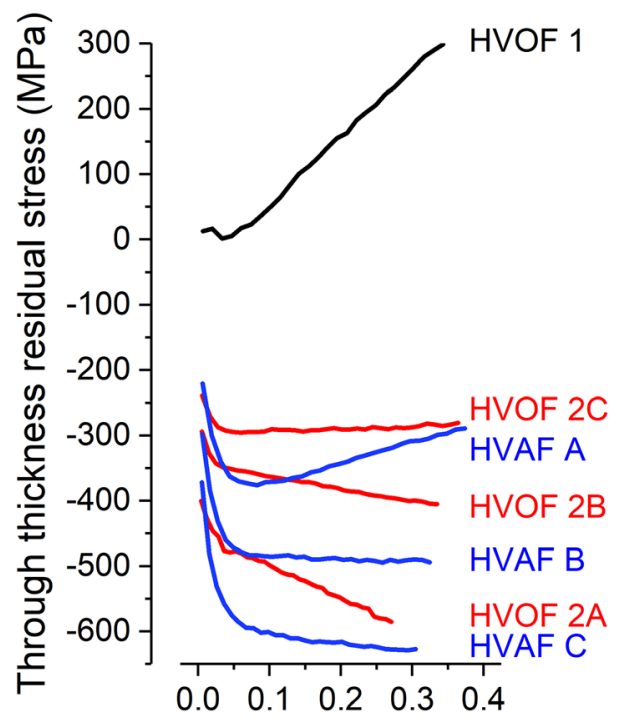

Coating thickness $(\mathrm{mm})$

Fig. 5 Through thickness residual stress profiles of the coatings by Tsui-Clyne analytical model. Substrate is on the left side initiated cracks were observed. Examination of the wear surfaces showed that cavitation erosion of the coatings takes place by fatigue crack growth preferably along the weak lamellae boundaries and removal of fractured areas, similarly as shown by Matikainen et al. (Ref 13) and Lamana et al. (Ref 15). The maximum depth of the wear scar shown in topography images (Fig. 7) was 60-70 $\mu \mathrm{m}$ for HVOF 1 coating, 20-30 $\mu \mathrm{m}$ for HVOF $2 \mathrm{~A}$ coatings, and $10-15 \mu \mathrm{m}$ for HVAF C coating. Thus, the crack growth rate was clearly the highest with HVOF 1 coating, next highest with HVOF 2 coating and slowest with HVAF coating.

\section{Discussion}

\section{Residual Stresses}

In the present study, the curvature data from the deposition process was used for determination of deposition stress and real temperature data from in situ curvature device for determination of thermal mismatch stress. This data was used for residual stress calculation with the Tsui and Clyne 
Table 4 Mechanical properties and wear resistances of the coatings

\begin{tabular}{|c|c|c|c|c|c|}
\hline & $\begin{array}{l}\text { Vickers hardness } \\
\quad(0.3 \mathrm{~kg})\end{array}$ & $\begin{array}{c}\text { Elastic } \\
\text { modulus, GPa }\end{array}$ & $\begin{array}{l}\text { Fracture toughness (crack type*), } \\
\qquad \mathrm{MPa} \mathrm{m}^{1 / 2}\end{array}$ & $\begin{array}{l}\text { Cavitation erosion resistance, } \\
\min \mu \mathrm{m}^{-1}\end{array}$ & $\begin{array}{l}\text { Abrasion resistance, } \\
\text { min } \mathrm{mm}^{-3}\end{array}$ \\
\hline HVOF 1 & $1455 \pm 198$ & $303 \pm 29$ & $4.6 \pm 1.3(P$ or $M)$ & 18.4 & 42.1 \\
\hline $\begin{array}{l}\text { HVOF } 2 \\
\text { A }\end{array}$ & $1400 \pm 195$ & $306 \pm 32$ & $5.4 \pm 0.5(P)$ & 91.0 & 49.8 \\
\hline $\begin{array}{l}\text { HVOF } 2 \\
\text { B }\end{array}$ & $1395 \pm 125$ & $318 \pm 26$ & $6.5 \pm 1.0(P)$ & 90.0 & 48.1 \\
\hline $\begin{array}{l}\text { HVOF } 2 \\
\mathrm{C}\end{array}$ & $1355 \pm 192$ & $301 \pm 8$ & $6.1 \pm 0.6(P)$ & 75.0 & 47.6 \\
\hline $\begin{array}{l}\text { HVAF } \\
\text { A }\end{array}$ & $1505 \pm 119$ & $396 \pm 25$ & $7.2 \pm 1.3(P)$ & 134.5 & 47.1 \\
\hline $\begin{array}{l}\text { HVAF } \\
\text { B }\end{array}$ & $1591 \pm 56$ & $375 \pm 62$ & $5.5 \pm 0.9(M)$ & 177.8 & 47.1 \\
\hline $\begin{array}{l}\text { HVAF } \\
\mathrm{C}\end{array}$ & $1691 \pm 97$ & $359 \pm 21$ & $2.4 \pm 0.4(M)$ & 209.0 & 46.1 \\
\hline
\end{tabular}

*P for radial Palmqvist cracks when $c / a<2.5$ and $M$ for median crack, when $c / a>2.5$
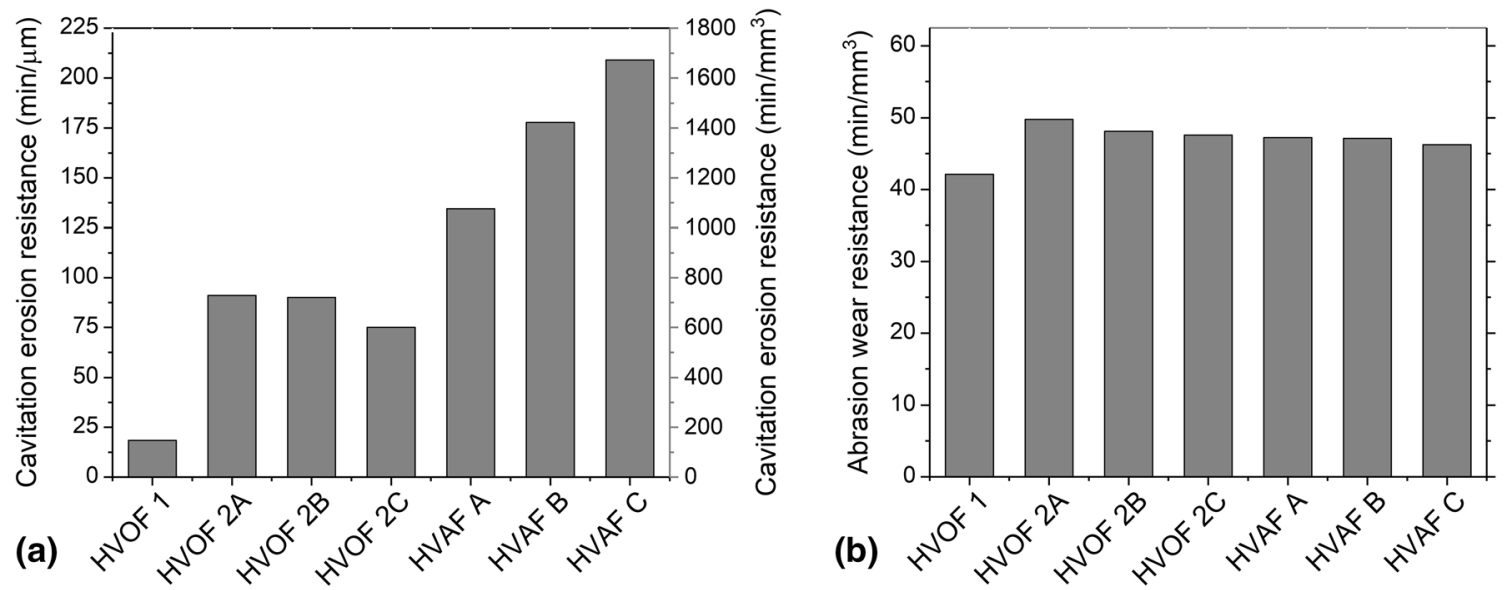

Fig. 6 (a) ASTM G 32 cavitation wear resistance and (b) ASTM G65D abrasion resistance of the coatings

procedure layer by layer. It was found, that residual stresses calculated by using Brenner and Senderoff approximation and Tsui Clyne model showed mostly similar tendencies. However, it was evident that the Brenner and Senderoff's equation overestimated especially the thermal mismatch stresses quite much. This result corresponds to the error analyses of Zhang et al. (Ref 39) regarding the use of Brenner and Senderoff equation for relatively hard coating with high thickness ratio of coating and substrate. They stated, that in the worst-case residual stress values can be overestimated approximately $30 \%$ using this method. However, in this case most of the errors for Brenner and Senderoff calculations came from the temperature increase during the first 3-5 passes. Temperature increase in the beginning causes the positive curvature change and hence shifts the deposition stresses, which are determined from curvatures between "start spray" and "end spray" (Fig. 3), toward the tensile stresses and thus exaggerates the thermal mismatch stresses by increasing the "end spray" curvature. If the temperature could have been kept constant during the deposition the difference between Brenner and Senderoff and Tsui and Clyne calculations would probably have been less.

Analytical model as per Tsui and Clyne had two advantages compared to Brenner and Senderoff calculation: (a) it represents through thickness residual stresses for progressively deposited coatings and (b) stresses arising from different origins can be evaluated. However, this requires that the deposition stresses and temperature change during the spraying process can be defined realistically by using real data from the deposition, which can be done by using an ICP sensor. It was clear that the temperature data during the spraying is significant for the resulting final stress state. Thus, in this case, the substrate 

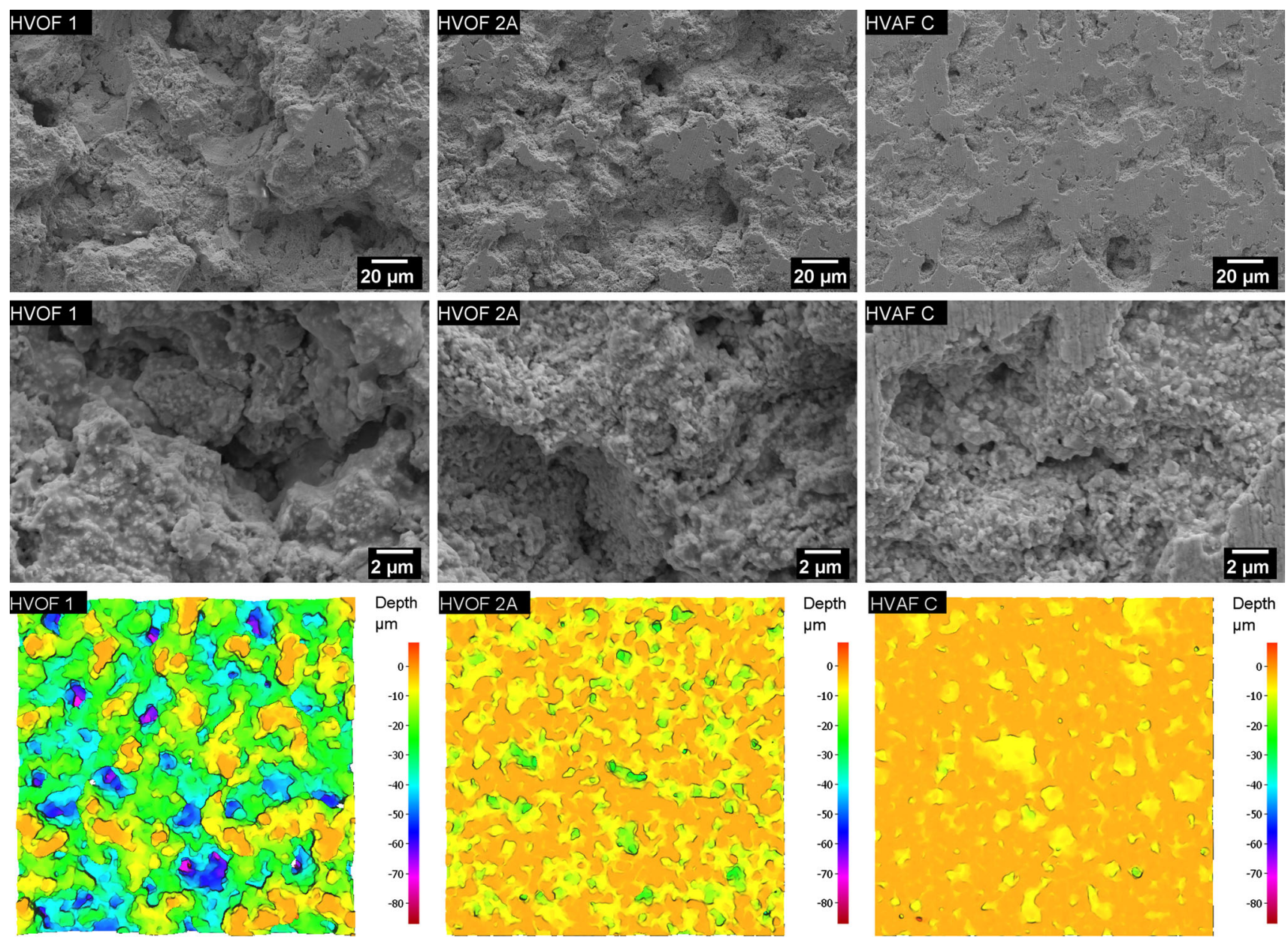

Depth
$\mu \mathrm{m}$
$0-$
$-10-$
$-20-$
$-30-$
$-40-$
-50
-60
-70
-80

Fig. 7 SEM and optical profilometer images of cavitation erosion surfaces of the HVOF 1-, HVOF 2A- and HVOF 2C-coatings

temperature data from the beginning of each pass was used. Considering the temperatures, it was evident that the HVAF process heats up the substrates more effectively than the two HVOF systems used in this work. Therefore, the high substrate temperature, which in this case created compressive thermal stresses due to CTE differences of coating and substrate materials, was the main reason for extremely high compressive residual stresses in the HVAF coatings. In the experiments, the temperatures of the substrates were under $230{ }^{\circ} \mathrm{C}$ for HVOF systems as they were between 280 and $340{ }^{\circ} \mathrm{C}$ when the HVAF system was used. High temperature of the HVAF substrates was certainly affecting the residual stresses, and it should be noted that these high temperatures are usually not possible in industrial coatings in cases where the workpieces are large, or the dimensions of the workpieces are critical. In this regard, the substrate temperatures in this study might not correspond exactly to those demanded in industry. However, the residual stress profiles presented here are realistic for the current sample geometry.
From the residual stress profiles in Fig. 5 and deposition stresses from Table 3, it can be seen that using the DJH 2700 HVOF (HVOF 1) process creates tensile stresses, which increase toward the surface of the coatings as the number of passes increase. In the CJS HVOF (HVOF 2) and Kermetico AK7 HVAF-processes, the peening stresses were dominant and the final residual stress states were compressive. The compressive deposition stresses (peening stresses) increased along with a lowered thickness/pass, which shows that the stresses here were related to the heat transfer onto the particles. However, the amount of heat transfer could not be deduced from the surface temperatures of the particles. Actually, it was found that in the HVOF 2 process the peening stresses (compressive deposition stresses) were of higher amount compared to HVAF process although the particle surface temperature in the HVOF 2 process was higher. The explanation for this can most likely be the particle dwell time, which is different in these spray guns due to the particle feeding location. In the CJS (HVOF 2) -process, the particles were fed radially into the nozzle, while in Kermetico AK7 HVAF and DJH 
(HVOF 1) processes, the powder was injected axially into the combustion chamber. This resulted in a shorter dwell time for particles in the HVOF 2 process compared to the HVAF process. Albeit the higher flame temperature (and particle surface temperature) the dwell time kept the particle melting rate lower, which meant lower deposition efficiency and a higher peening effect. Furthermore, it was found that for HVAF process the lowest particle surface $\mathrm{T}$ parameter produces the highest tensile deposition stress, which can also be explained by the dwell time effect. Decrease of the total gas flows in HVAF increases the dwell time of the particles and therefore melting rate increases. This can also be witnessed by highest thickness/pass with HVAF A parameter.

\section{Mechanical Properties}

Hardness and elastic modulus were on a good level for all of the coatings, but the highest elastic modulus and hardness were clearly achieved with HVAF coatings. Hardness and elastic modulus of thermally sprayed coatings typically increase, when the coating is denser. However, the hardness of a WC-CoCr coating may increase as well if the particle temperature has been sufficiently high to create hard and brittle secondary phases in the matrix (e.g., eta phase) and on the surface of carbides $\left(\mathrm{W}_{2} \mathrm{C}\right)$ by carbon loss and carbide dissolution (Ref 38, 40). By looking at the microstructure and considering that the HVOF 1 coating was the only coating, which had significant amount of $\mathrm{W}_{2} \mathrm{C}$ in the XRD analysis, it can be proposed that its high hardness is a result of the high spray temperature. For the HVOF 2 and HVAF coatings, the microstructures were extremely dense and no major $\mathrm{W}_{2} \mathrm{C}$ was found. From the microstructure, a high amount of retained small carbides was detectable too, which may partly explain the good mechanical properties of HVAF coatings. Obviously, the significant advantage of the HVAF and HVOF 2 coatings is the achievement of very good mechanical properties by relying on their high density and structural homogeneity without a risk of formation of brittle phases.

The good mechanical properties and wear resistance of thermally sprayed coatings are to be improved by the wellbonded lamellae. Lamellae boundaries often weaken thermally sprayed coatings, which resembles grain boundaries in solid material. In particular, the high elastic modulus and high hardness (without significant $\mathrm{W}_{2} \mathrm{C}$ formation) of HVAF-coatings indicate good lamella cohesion. In this study, the lamellae cohesion was further evaluated by indentation fracture toughness measurements, in which the cracks were formed from the edge of Vickers tip. It was earlier found that Palmqvist type of cracks initiating from the edge of the Vickers indenter tip usually follow the path of lamellae boundaries. Hence, fracture toughness, which is measured from the cross section of the coating, is linked to the lamellae cohesion (Ref 40). In the current study, there was no indication of improved cross section fracture toughness for coatings, which had excellent other mechanical properties. In contrast, fracture toughness of coatings HVAF B and C was clearly reduced. For these coatings, the thermal mismatch stresses were -373 to $436 \mathrm{MPa}$, respectively. In order to understand the observed reduction of fracture toughness's linked to high compressive stress the occurrence of cracking under indentation needs to be discussed. Indenting the material with relatively small loads the plastic deformation at the edge of the Vickers tip creates usually Palmqvist type cracks. These cracks initiates at the edge of the indenter and develop in the surface of the material driven by tensile stresses when the lateral faces of the Vickers tip push the material in different directions (Ref 41). Palmqvist cracks are addressed to be present if ratio of average crack length to indenter half diagonal $(c / a)$ is $<2.5$ (Ref 42). Median cracks are formed with higher loads. First, a plastic zone is formed under the indenter and if the load is increased enough the median cracks parallel to the loading direction are formed under the plastic zone (Ref 41, 43). During the unloading plastic zone do not relax and stress field remains and is responsible of development of the "half-penny" cracks onto a surface (Ref 41). These cracks are visible at the same locations on the sample surface as Palmqvist cracks and are addressed to be present if $c / a>2.5$ (Ref 42). Considering the high compressive stresses in the HVAF and HVOF 2 coatings it is obvious that in our case they have an influence on the crack initiation and growth. When hardness measurement is made on the cross section of the coating, it is likely that compression at the crack tip hinders the crack growth at the Palmqvist crack region. On the other hand, compressive stresses parallel to indentation direction increases the depth of plastic region and thus median cracks develop deeper into the material resulting to longer "half- penny"-cracks as they develop onto the surface (Ref 44-46). It is conceivable that, due to the stress state in the coating," half-penny"-cracks become more favorable. Since the effect of the stress state on the formation of indentation cracks was not the scope of this study, it is sufficient to state that due to the strong effect of the residual stresses in the coatings on the indentation fracture toughness measurements, the fracture toughness values cannot be considered comparable figures without taking into account of these residual stresses.

It was further noted that high compressive stresses did not reduce the fracture toughness of the HVOF $2 \mathrm{~A}$ coating, which had high compressive residual stress (- $580 \mathrm{MPa})$ on the coating surface as well. On this basis it may be suggested that HVOF $2 \mathrm{~A}$ had either better lamella cohesion compared to HVAF B and $\mathrm{C}$ or then the way the tensile 
stress is created (peening or CTE mismatch) has an effect. It may be possible that the residual stresses generated from the peening are not that detrimental in terms of crack propagation due to their local nature. In contrast, thermal mismatch stresses uniformly affect the entire structure and provide steady stress field under the indentation tip for the formation of longer half-penny cracks.

\section{Wear}

Cavitation erosion resistance results varied considerably between different coatings. In addition, the cavitation erosion resistance of the HVAF coatings was superior compared to the both HVOF coatings. These results are consistent with the findings of other recent studies carried out on WC-10Co4Cr coatings (Ref 13, 15, 47). Matikainen et al. that the cavitation erosion performance of the coatings can be improved by increasing kinetic energy and decreasing particle temperature from $\mathrm{HVOF}$ to $\mathrm{HP} / \mathrm{HVOF}$ to HVAF, which they linked to higher density and lower degree of decarburization. Similar results have been found in other studies as well (Ref 47). Based on the results in this study, seems evident that the high compressive residual stress state of these coatings plays a very important role in improved cavitation erosion resistance. This suggestion is supported by a higher cavitation erosion resistance of the HVOF 2 an HVAF coatings, which showed compressive residual stresses compared to the HVOF 1 coating, which were characterized by tensile residual stresses. Moreover, the cavitation erosion resistance increased for the HVOF 2 and HVAF processes, when compressive residual stress increased too. Cavitation erosion can be considered as a cyclic fatigue load caused by continuous collapsing of cavitation bubbles on the surface. Therefore, the erosion rate is controlled by fatigue crack growth mechanism preferably along the weak lamellae boundaries and a rate of removal of fractured areas. Probably the high compressive stresses resulted from the spraying process of the WC$\mathrm{CoCr}$ coatings impede the fatigue crack formation and growth along the lamellae interfaces and therefore improve the cavitation erosion resistance, which is supported by the literature (Ref 15). Furthermore, it may be more advantageous if the compressive stresses are originated from thermal stresses rather than peening stress, since the stress in previous case is more homogeneous and acts at the macro-level. This may explain the improved performance of the HVAF coating over the HVOF 2 coatings.

The influence of other factors on the good cavitation erosion performance may be important as well. Considering the cavitation erosion resistance of solid material, in addition to hardness, the strain-hardening ability of material plays an important role in resisting the crack growth caused by pressure of the collapsing cavitation bubbles.
The CoCr matrix in solid WC-CoCr has a relatively high strain-hardening exponent and thus resists cavitation well. However, the thermally sprayed WC-CoCr coatings always reveal some amount of the dissolution of the WC into the matrix, which increases the tendency of formation of mixed $(\mathrm{Co}, \mathrm{W})_{\mathrm{x}} \mathrm{C}$-carbides or amorphous phases during the rapid cooling. Hence, the matrix is not an optimally composed metal alloy, but instead hardened and more brittle. Based on the microstructure and XRD it seems evident that less solution occurs in the HVAF and HVOF 2 coatings compared to the HVOF 1 coatings and that spraying conditions do not affect the properties as much as compared to HVOF 1. It is known that too much carbide dissolution into the matrix can decrease the fracture toughness of the matrix (Ref 40), which may result to the poor cavitation erosion performance of HVOF 1. Actually, Matikainen et al. (Ref 13) showed that especially brittle phases in HVOF-sprayed coatings are susceptible to brittle fractures. In addition, the lamellae cohesion is commonly believed to affect the wear performance of the thermally sprayed coatings. Superior performance of the HVAF and HVOF 2 coatings might be therefore partly related to optimal particle heating. This results in good lamellae cohesion and lack of brittle areas inside the coatings and thus hinders brittle fracture in the lamellae interfaces. Lamana et al. (Ref 15) showed that fatigue cracking caused by cavitation mainly began at the interface between the lamellae and found a strong correlation between fracture toughness measured at the cross section of the specimens and cavitation erosion resistance of the coatings. In this study, such a correlation could not be demonstrated since residual stress state was found to significantly influence the fracture toughness measured from the coating cross section. Perhaps, a better correlation might have been obtained if the fracture toughness had been measured from the surface of the coating, since the cracks produced would then have been initiated correspondingly to those generated by cavitation. However, this was not possible, because very high loads and thus thick coatings would have been needed that such an experiment could have been done.

With respect to abrasive wear resistance, it was relatively unaffected by the used spray process, and residual stresses and the spray parameters. Only the abrasion wear resistance of HVOF 1 coating was slightly lower compared to HVOF 2 and HVAF coatings. In order to consider, the removed material volumes in various wear tests in Fig. 6(a) and (b), it should be noted that in abrasion tests the wear area is about twice as large as in cavitation erosion test. Proportional to the same area material removal rate for most worn sample (HVOF 1) in abrasion test is roughly two times more than in cavitation test. The most cavitation-resistant coating the material removal rate is approximately 20 times higher in abrasion test. The large 
difference in wear rates between tests can be explained by a different wear mechanism. Considering the abrasion wear the proposed mechanism is mainly micro-cutting, i.e., sand particle needs to penetrate on the material and remove the material from the surface in the form of a chip (Ref 48). Therefore, in the abrasion test unlike the cavitation erosion test, the wear rate is not controlled by fatigue crack growth and it is not surprising that residual stresses do not have effect on abrasion wear rate. Rather, the abrasion wear rate is controlled by such factors as hardness of the softest phase in material, carbide size related to the abrasive size, mean free path of carbides related to the abrasive size. For thermally sprayed WC-CoCr, the wear may further be affected by the factors related to spray process such as porosity, lamellae adhesion, toughness reduction/hardening of matrix due to the dissolution of carbides onto a matrix, which may explain the minor differences between HVAF and HVOF 2 coatings. The surface porosity may be in this case an important factor, which may explain the lower wear resistance of HVOF 1 coating, which had larger size porosity in the microstructure. The abrasive particles can more easily cut the chip from the material from the edge of the pore as presented by Ghabchi et al. (Ref 49). However, it may be concluded that the abrasion resistance was good for all of the coatings and the coating characteristics did not affect significantly on abrasion wear resistance.

\section{Conclusions}

In the study, the residual stress state of the high kinetic thermal spray processes such as high-pressure HVOF and HVAF were compared to conventional thermal spray processes. Residual stress state of WC-CoCr coatings was determined by Tsui and Clyne laye-by-layer analytical model. The in-situ coating property device was utilized to determine the realistic quenching stress and temperature data as input to the analytical model. By this way, a realistic through thickness calculation of residual stresses was achieved. Cavitation erosion, abrasion wear and mechanical property tests were conducted, and the effect of the residual stress state on the wear resistance and mechanical performance was discussed.

Following conclusions were made from the study:

- The analytical residual stress model by Tsui and Clyne combined with the data from ICP curvature and temperature-sensing device allows for the determination the through thickness residual stress state of the coating. However, to achieve a result the specific flat bar samples needs to be used. Compared to the values achieved by Brenner and Senderoff equation, which is commonly used for average residual stress approximation, the final residual compressive stresses were significantly lower.

- The spray parameters of the Kermetiko AK7 and Thermico CJS high kinetic thermal spray processes can be adjusted to produce compressive deposition stresses. For DJ Hybrid, the deposition stress was tensile. As a result, relatively high compressive final stress states inside the WC-CoCr coatings can be achieved by the high kinetic processes and altered significantly by spraying parameters. In this study, the final compressive stress state at the surface of coating, determined by Tsui and Clyne analytical model, altered from - 289 to - $628 \mathrm{MPa}$ for the AK7 HVAF process and form -281 to $-586 \mathrm{MPa}$ in the case of Thermico CJS (HVOF 2) process.

- Thermally sprayed WC-10Co4Cr coatings sprayed by high-pressure HVOF and HVAF processes can provide significant performance improvements in cavitation erosion resistance. The cavitation erosion resistance of the HVAF-sprayed coatings was 7-11 times higher and for high-pressure HVOF still 4-5 times higher compared to conventional gas-fuelled HVOF processes.

- Superior cavitation erosion resistance of the HVAF and high-pressure HVOF coatings was partly a result from the dense and homogenous non-brittle microstructure. Moreover, it seems that the most important factor behind the superior cavitation erosion resistance might probably be the high compressive residual stress state in the coatings. The high compressive stresses make the fatigue crack formation more difficult and hinder the fatigue crack growth along the lamellae interfaces and in this way improves the cavitation erosion resistance.

Open Access This article is licensed under a Creative Commons Attribution 4.0 International License, which permits use, sharing, adaptation, distribution and reproduction in any medium or format, as long as you give appropriate credit to the original author(s) and the source, provide a link to the Creative Commons licence, and indicate if changes were made. The images or other third party material in this article are included in the article's Creative Commons licence, unless indicated otherwise in a credit line to the material. If material is not included in the article's Creative Commons licence and your intended use is not permitted by statutory regulation or exceeds the permitted use, you will need to obtain permission directly from the copyright holder. To view a copy of this licence, visit http://creativecommons. org/licenses/by/4.0/.

\section{References}

1. S. Sampath, X.Y. Jiang, J. Matejicek, L. Prchlik, A. Kulkarni, and A. Vaidya, Role of Thermal Spray Processing Method on the Microstructure, Residual Stress and Properties of Coatings: An Integrated Study of Ni-5 wt. \% Al Bond Coats, Mater. Sci. Eng. $A, 2004$, 364(1-2), p 216-231 
2. J. Matejicek, S. Sampath, D. Gilmore, and R. Neiser, In Situ Measurement of Residual Stresses and Elastic Moduli in Thermal Sprayed Coatings Part 2: Processing Effects on Properties of Mo Coatings, Acta Mater., 2003, 51(3), p 873-885

3. T.W. Clyne and S.C. Gill, Residual stresses in Thermal Spray Coatings and Their Effect on Interfacial Adhesion: A Review of Recent Work, J. Therm. Spray Technol., 1996, 5, p 401-418

4. V. Matikainen, H. Koivuluoto, P. Vuoristo, J. Schubert, and Š. Houdková, Effect of Nozzle Geometry on the Microstructure and Properties of HVAF-Sprayed WC-10Co4Cr and $\mathrm{Cr} 3 \mathrm{C} 2-25 \mathrm{NiCr}$ Coatings, J. Therm. Spray Technol., 2018, 27(4), p 680-694

5. W. Luo, U. Selvadurai, and W. Tillmann, Effect of Residual Stress on the Wear Resistance of Thermal Spray Coatings, $J$. Therm. Spray Technol., 2016, 25(1-2), p 321-330

6. R.C. Souza, H.J.C. Voorwald, and M.O.H. Cioffi, Fatigue Strength of HVOF Sprayed $\mathrm{Cr} 3 \mathrm{C} 2-25 \mathrm{NiCr}$ and $\mathrm{WC}-10 \mathrm{Ni}$ on AISI, 4340 Steel, Surf. Coatings Technol., 2008, 203(3-4), p 191198

7. R.T.R. McGrann, D.J. Greving, J.R. Shadley, E.F. Rybicki, T.L. Kruecke, and B.E. Bodger, The Effect of Coating Residual Stress on the Fatigue Life of Thermal Spray-Coated Steel and Aluminum, Surf. Coat. Technol., 1998, 108-109(1-3), p 59-64

8. T. Varis, T. Suhonen, O. Calonius, J. Čuban, and M. Pietola, Optimization of HVOF Cr3C2-NiCr Coating for Increased Fatigue Performance, Surf. Coat. Technol., 2016, 305, p 123-131

9. A. Agüero, F. Camón, J. García De Blas, J.C. Del Hoyo, R. Muelas, A. Santaballa, S. Ulargui, and P. Vallés, HVOF-Deposited WCCoCr as Replacement for Hard $\mathrm{Cr}$ in Landing Gear Actuators, J. Therm. Spray Technol., 2011, 20(6), p 1292-1309

10. R.K. Kumar, M. Kamaraj, S. Seetharamu, T. Pramod, and P. Sampathkumaran, Effect of Spray Particle Velocity on Cavitation Erosion Resistance Characteristics of HVOF and HVAF Processed 86WC-10Co4Cr Hydro Turbine Coatings, J. Therm. Spray Technol., 2016, 25(6), p 1217-1230

11. G. Bolelli, L.M. Berger, T. Börner, H. Koivuluoto, L. Lusvarghi, C. Lyphout, N. Markocsan, V. Matikainen, P. Nylén, P. Sassatelli, R. Trache, and P. Vuoristo, Tribology of HVOF- and HVAF-Sprayed WC-10Co4Cr Hardmetal Coatings: A Comparative Assessment, Surf. Coatings Technol., 2015, 265, p 125-144

12. V. Matikainen, G. Bolelli, H. Koivuluoto, P. Sassatelli, L. Lusvarghi, and P. Vuoristo, Sliding Wear Behaviour of HVOF and HVAF Sprayed Cr3C2-Based Coatings, Wear, 2017, 388389(April), p 57-71. https://doi.org/10.1016/j.wear.2017.04.001

13. V. Matikainen, S. Rubio Peregrina, N. Ojala, H. Koivuluoto, J. Schubert, S. Houdková, and P. Vuoristo, Erosion Wear Performance of WC-10Co4Cr and $\mathrm{Cr} 3 \mathrm{C} 2-25 \mathrm{NiCr}$ Coatings Sprayed with High-Velocity Thermal Spray Processes, Surf. Coat. Technol., 2018, 2019(370), p 196-212

14. H.K.R. Schwetzke, Cavitation Erosion of HVOF Coatings, Thermal Spray: Practical Solutions for Engineering Problems, C.C. Berndt, Ed., ASM International, Cleveland, 1996, p 153-158

15. M.S. Lamana, A.G.M. Pukasiewicz, and S. Sampath, Influence of Cobalt Content and HVOF Deposition Process on the Cavitation Erosion Resistance of WC-Co Coatings, Wear, 2017, 2018(398399), p 209-219. https://doi.org/10.1016/j.wear.2017.12.009

16. S. Takeuchi, M. Ito, and K. Takeda, Modelling of Residual Stress in Plasma-Sprayed Coatings: Effect of Substrate Temperature, Surf. Coat. Technol., 1990, 43-44(PART 1), p 426-435

17. S. Kuroda, T. Fukushima, and S. Kitahara, Significance of Quenching Stress in the Cohesion and Adhesion of Thermally Sprayed Coatings, J. Therm. Spray Technol., 1992, 1(4), p 325332

18. P. Bansal, P.H. Shipway, and S.B. Leen, "Effect of Particle Impact on Residual Stress Development in HVOF Sprayed Coatings," Proceedings of the International Thermal Spray Conference, 2006, p 570-575.
19. S. Kuroda and T.W. Clyne, The Quenching Stress in Thermally Sprayed Coatings, Thin Solid Films, 1991, 200(1), p 49-66

20. S. Kuroda, T. Dendo, and S. Kitahara, Quenching Stress in Plasma Sprayed Coatings and Its Correlation with the Deposit Microstructure, J. Therm. Spray Technol., 1995, 4(1), p 75-84

21. S. Kuroda, Y. Tashiro, H. Yumoto, S. Taira, H. Fukanuma, and S. Tobe, Peening Action and Residual Stresses in High-Velocity Oxygen Fuel Thermal Spraying of 316L Stainless Steel, J. Therm. Spray Technol., 2001, 10(2), p 367-374

22. A.A. Abubakar, A.F.M. Arif, K.S. Al-Athel, S.S. Akhtar, and J. Mostaghimi, Modeling Residual Stress Development in Thermal Spray Coatings: Current Status and Way Forward, J. Therm. Spray Technol., 2017, 26(6), p 1115-1145

23. T. Valente, C. Bartuli, M. Sebastiani, and A. Loreto, Implementation and Development of the Incremental Hole Drilling Method for the Measurement of Residual Stress in Thermal Spray Coatings, J. Therm. Spray Technol., 2005, 14(4), p 462-470

24. Y.Y. Santana, J.G. La Barbera-Sosa, M.H. Staia, J. Lesage, E.S. Puchi-Cabrera, D. Chicot, and E. Bemporad, Measurement of Residual Stress in Thermal Spray Coatings by the Incremental Hole Drilling Method, Surf. Coat. Technol., 2006, 201(5), p 2092-2098

25. M. Buchmann, R. Gadow, and J. Tabellion, Experimental and Numerical Residual Stress Analysis of Layer Coated Composites, Mater. Sci. Eng. A, 2000, 288(2), p 154-159

26. M.S.J. Hashmi, Ed., Comprehensive Materials Processig, Elsevier Ltd, Amsterdam, 2014

27. A.S.M. Ang and C.C. Berndt, A Review of Testing Methods for Thermal Spray Coatings, Int. Mater. Rev., 2014, 59(4), p 179-223

28. G.G. Stoney, The Tension of Metallic Films Deposited by Electrolysis, Proc. R. Soc. A Math. Phys. Eng. Sci., 1909, 82(553), p 172-175

29. A. Brenner and S. Senderoff, Calculation of Stress in Electrodeposits from the Curvature of a Plated Strip, J. Res. Natl. Bur. Stand., 1949, 42(2), p 105

30. Y.C. Tsui and T.W. Clyne, An Analytical Model for Predicting Residual Stresses in Progressively Deposited Coatings: Part 1Planar Geometry, Thin Solid Films, 1997, 306(1), p 23-33

31. D.J. Greving, E.F. Rybicki, and J.R. Shadley, Through-Thickness Residual Stress Evaluations for Several Industrial Thermal Spray Coatings Using a Modified Layer-Removal Method, J. Therm. Spray Technol., 1994, 3(4), p 379-388

32. T.C. Totemeier and J.K. Wright, Residual Stress Determination in Thermally Sprayed Coatings - A Comparison of Curvature Models and X-Ray Techniques, Surf. Coat. Technol., 2006, 200(12-13), p 3955-3962

33. J. Pina, A. Dias, and J.L. Lebrun, Study by X-Ray Diffraction and Mechanical Analysis of the Residual Stress Generation during Thermal Spraying, Mater. Sci. Eng. A, 2003, 347(1-2), p 21-31

34. C. Lyphout, P. Nylén, A. Manescu, and T. Pirling, Residual Stresses Distribution through Thick HVOF Sprayed Inconel 718 Coatings, J. Therm. Spray Technol., 2008, 17(5-6), p 915-923

35. G.M. Pharr, An Improved Technique for Determining Hardness and Elastic Modulus Using Load and Displacement Sensing Indentation Experiments, J. Mater. Res., 1992, 7(6), p 1564-1583

36. James Lanklord, Indentation Microfracture in the Palmqvist Crack Regime: Implications for Fracture Toughness Evaluation by the Indentation Method, J. Mater. Sci. Lett., 1982, 1, p $493-$ 495

37. Y.C. Tsui and T.W. Clyne, An Analytical Model for Predicting Residual Stresses in Progressively Deposited Coatings: Part 3Further Development and Applications, Thin Solid Films, 1997, 306(1), p 52-61

38. C. Verdon, A. Karimi, and J.L. Martin, A Study of High Velocity Oxy-Fuel Thermally Sprayed Tungsten Carbide Based Coatings. 
Part 1: Microstructures, Mater. Sci. Eng. A, 1998, 246(1-2), p 1124

39. X.C. Zhang, B.S. Xu, H.D. Wang, and Y.X. Wu, Error Analyses on Some Typically Approximate Solutions of Residual Stress within a Thin Film on a Substrate, J. Appl. Phys., 2005, 98(5), p 053516

40. T. Varis, T. Suhonen, A. Ghabchi, A. Valarezo, S. Sampath, X. Liu, and S.P. Hannula, Formation Mechanisms, Structure, and Properties of HVOF-Sprayed WC-CoCr Coatings: An Approach toward Process Maps, J. Therm. Spray Technol., 2014, 23(6), p 1009-1018

41. R.F. Cook, Fracture Sequences during Elastic-Plastic Indentation of Brittle Materials, J. Mater. Res., 2019, 34(10), p 1633-1644

42. C.B. Ponton and R.D. Rawlings, Vickers Indentation Fracture Toughness Test Part 1 Review of Literature and Formulation of Standardised Indentation Toughness Equations, Mater. Sci. Technol. (United Kingdom), 1989, 5(9), p 865-872

43. T. Fett, A.B. Kounga Njiwa, and J. Rödel, Crack Opening Displacements of Vickers Indentation Cracks, Eng. Fract. Mech., 2005, 72(5), p 647-659

44. W.G. Mao, J. Wan, C.Y. Dai, J. Ding, Y. Zhang, Y.C. Zhou, and C. Lu, Evaluation of Microhardness, Fracture Toughness and
Residual Stress in a Thermal Barrier Coating System: A Modified Vickers Indentation Technique, Surf. Coat. Technol., 2012, 206(21), p 4455-4461

45. C.L. Eriksson, P.L. Larsson, and D.J. Rowcliffe, Strain-Hardening and Residual Stress Effects in Plastic Zones around Indentations, Mater. Sci. Eng., 2003, 340(1-2), p 193-203

46. N. Huber and J. Heerens, On the Effect of a General Residual Stress State on Indentation and Hardness Testing, Acta Mater., 2008, 56(20), p 6205-6213

47. Q. Wang, Z. Tang, and L. Cha, Cavitation and Sand Slurry Erosion Resistances of WC-10Co-4Cr Coatings, J. Mater. Eng. Perform., 2015, 24(6), p 2435-2443

48. K.H.Z. Gahr, Wear by Hard Particles, Tribol. Int., 1998, 31(10), p 587-596

49. A. Ghabchi, T. Varis, E. Turunen, T. Suhonen, X. Liu, and S.P. Hannula, Behavior of HVOF WC-10Co4Cr Coatings with Different Carbide Size in Fine and Coarse Particle Abrasion, $J$. Therm. Spray Technol., 2010, 19(1-2), p 368-377

Publisher's Note Springer Nature remains neutral with regard to jurisdictional claims in published maps and institutional affiliations. 